\title{
COOPERATIVE GAME THEORY APPROACH TO ESTABLISHING A LANDSCAPE AGREEMENT
}

\author{
Kenichi SHIMAMOTO \\ Konan University, Japan
}

\begin{abstract}
As the need for a participatory approach towards a sustainable landscape development grows, this paper has applied the cooperative game theory to analyse the mechanism of entering a landscape agreement which requires the participation and initiative of local residents and stakeholders. The results confirmed that a landscape agreement only becomes possible with a certain level of supporters and the optimal situation is when all participants agree. Moreover, the possibility of free riders, which would prevent reaching a universal agreement, was also confirmed. The effect of government subsidies for landscape considerate building and the enforcement of penalties for building without were also examined. As a result, we learned that subsidies and the enforcement of penalties influences the number of supporters required for the landscape agreement and in preventing free riders.
\end{abstract}

Key Words: landscape agreement, subsidy, penalty, free rider..

\section{Introduction}

Landscape change is a result of the dynamic interaction between natural and cultural forces in the environment and adapting to the changing societal demands (Antrop 2005). Thus, sustainable landscape planning and development does not only require landscape protection, but also the participation of the local residents in shaping the landscape (Buchecker et al. 2003). However, it is not until recent years that local stakeholders have an opportunity to play a role in landscape planning. Landscape planning is now shifting from the traditional top-down approach into a bottom-up and integrated approach involving the participation of local stakeholders (Sevenant and Antrop 2010, Butler and Åkerskog 2014). The European Landscape Convention (Council of Europe 2008) also recognises the importance of a participatory approach in landscape planning. Japan is no exception. Tough in the past, it has taken a uniform development approach across the nation with emphasis on development and liberal building regulations ${ }^{1)}$ and landscape consideration was not a priority at the time ${ }^{2)}($ Saita et al. 2014). However, in 2004, the Landscape Act, which encourages the consideration of the landscape in developments was established. Article 81 and 91 of this Act encourages the formation of landscape agreements as an effective measure to preserve and develop landscapes with the involvement of the local residents and stakeholders ${ }^{3)}$ (Hoshi and Kawasaki

1) An owner has the rights to freely use, obtain profit from and dispose of the thing owned, subject to the restrictions prescribed by laws and regulations (Civil Code, Article 206). Hence, land owners are able to build freely on their land. However, lands are connected and if landscapes were to be considered common property to all citizens, as a principle, a certain level of restrictions or adjustments to interests should be allowed as a public law.

2) For example, from the first National Comprehensive Development Plan to the second National Comprehensive Development Plan, the development of foundations for economic activities such as industries and transportation infrastructure were promoted. Concerning the landscape, it was not until the 1990s that landscape ordinances in regions were actively established and it took until 2004 for the Landscape Act to be established on a country level. However, with the Act on Special Measures concerning the Preservation of Traditional Scenic Beauty in Ancient Capitals established in 1966 to protect Kyoto, Nara and Kamakura, historical buildings and landscapes have been actively preserved from the 1970s (Sato 2011). 
2014). A landscape agreement is a system that enables the local residents and other stakeholders to establish building restrictions within a landscape planning area in order to formulate an advanced and detailed standard for the landscape ${ }^{4)}$. This includes buildings and the environment such as architectural structures and other structures, woodlands, meadows, forestation, outdoor advertising and farmland. Hence, a landscape agreement has significance since it provides the local residents and stakeholders with the ability to proactively protect and plan the landscape of the community by establishing landscape restrictions ${ }^{5}$.

This paper has studied the landscape agreement which is a participatory method for local stakeholders to be involved and take ownership concerning the landscape. Past studies on landscape have focused on the hedonic pricing model to place a value on landscape features. Since the amenity value of landscapes often lack a market price, these studies attempt to quantify the monetary value of landscape features such as green space (Geoghegan et al. 1997, Garrod 2007, Kong et al. 2007, Sander and Polasky 2009). With regard to participation, since landscape is an issue which affects the whole population and the care for the landscape requires collaboration between a wide range of individuals and organisations, the need for a participatory method to landscape planning is recognized and there are extensive studies on effective approaches and case studies from around the world (Buchecker et al. 2003, Höppner et al. 2007, Valencia-Sandoval et al. 2010, Conrad et al. 2011).

This paper has focused on the mechanism of entering into a landscape agreement using the cooperative game model for analysis. To the best of my knowledge, the cooperative game theory has not been applied to landscape agreements, though it has been used to study environmental issues such as pollution and global warming. For example, Carraro (1999) focuses on the challenges of achieving an international environmental agreement (IEA) which may not be profitable for all countries involved and the intrinsic instability of environmental agreements where free-riders are able to exist. There are extensive studies on IEAs using the tools of the cooperative coalition theory such as in the context of global warming (Chander and Tulkens 1995, 1997, Eyckmans and Tulkens 2003) and water management (Ambec and Sprumont 2002). IEAs are also analysed using the non-cooperative coalition theory to explain free-riding with the consideration of externalities, to identify the conditions of a partial cooperation and to find methods to discourage free-riding. For example, Carraro and Siniscalco (1998) discuss the mechanisms and strategies aimed at offsetting the incentives to free ride. However, at the international level, there is no authority that could implement and enforce environmental policies on sovereign states so the agreements need to be self-enforcing (loannidis et al. 2000). Further research has been conducted on how transfers can be used to the success of a self-enforcing agreement (Carraro and Siniscalco 2001, Bosello et al. 2003, Altamirano-Cabrera and Finus 2004, Carraro et al. 2006, Eyckmans and Finus 2006). Landscape planning and agreements can be implemented on a local level and addressed by the existing government bodies. From this perspective, applying the cooperative game theory to landscape agreements should be a unique addition to environmental studies, as well as landscape studies where research that applies the cooperative game theory is limited. Shapley and Shubik (1969) consider the external economies and diseconomies in the cooperative game and remarks on the possibility of taxation or subsidization schemes to restore optimality to the competitive market. This paper has studied this possibility and it has included in the model the impact of incentives to improve the landscape and penalties to promote landscape consideration. Subsidies may have the ability to work as an incentive to promote a certain

3) Though landscape ordinances have been led by local governments to tackle landscape issues, with the lack of supporting laws, they were limited to being administrative guidance and enforcement measures were not possible (Shimada 2013).

4) For example, the design of buildings and structures including colour and material.

5) Since landscape agreements are based on the Landscape Act, they are legally binding compared to the local government landscape ordinances or a normal agreement. 
action and a number of studies have been conducted on its effectiveness in economic and urban policies (Lindborg et al. 2008, Brunner and Huyton 2009, Wang et al. 2015, Zhao et al. 2016, Zhuo and Wei 2017). They are also being used to promote landscape agreements in Nagaoka, Japan, and there is a country side landscape subsidy applied in Iga, Japan. Penalties can play an important role in preventing certain illegal activities (Tanzi 1998). It is widely applied in the US to protect farmlands from being converted to nonfarm use (Wunderlich 1997).

The results have confirmed that the landscape agreement can only be formed when a certain level of supporters exists and the optimal situation is when there is a universal agreement. On the other hand, the possibility of the existence of free riders has been also identified, which can be the cause of preventing a universal agreement. This has led to the application of the cooperative game model to examine the effect of subsidies to promote landscape consideration and the effect of the enforcement of penalties for non-consideration and their contribution in promoting landscape agreements and restricting free riders. It has found that subsidies and enforcement of penalties enabled landscape agreements to be formed with a minimum level of support. The number of free riders was also controlled.

The remainder of the paper has been organised as follows. Section 2 applies the cooperative game approach to landscape agreements examining the effect subsidies and penalties have on the number of supporters of the landscape agreement and the number of free riders. Section 3 provides the results and conclusions.

\section{Methodology}

We have considered a landscape planning area. In this area, if households plan architecture that take the landscape into consideration before the construction starts, the cost per unit area is $U$ yen for each household. On the other hand, if the construction starts without taking the landscape into consideration, the cost such as from external diseconomy may be incurred. For example, according to the Broken Windows Theory (Wilson and Kelling 1982), the deterioration of the environment can have a number of negative impacts such as increased crime, decline in sanitation levels leading to further deterioration of the environment and a decline in land prices. Therefore, the burden of the cost for the improvement will fall on the households. We have assumed this cost to the households to be $V$ yen per unit area. If the construction of the household $x$ did not take the landscape into consideration, then the cost for improvement per unit area for each household is $x V$ yen.

\section{Results and Discussion}

Here, the set of players of the cooperative game model is defined as $N$. The subset of players within the set will be coalition $S$ and any other coalition has been represented as $N-S$. In this case, the number of members within coalition $S$ will be $s$ and the number of members in coalition $N$-S will be $n$-s. The cost function for each situation where coalition $S$ and coalition $N$ $S$ build with or without landscape consideration is represented in Table 1 below. The first equation in the top left of Table $1, s U$, refers to the cost to coalition $S$ when both coalition $S$ and coalition $\mathrm{N}-\mathrm{S}$ build with landscape consideration.

The second equation, $(n-s) U$, indicates the cost to coalition N-S, when both coalition $S$ and coalition N-S build with landscape consideration. The first equation in the top right,

$\mathrm{s}\{U+(n-s) V\}$, represents the cost to coalition $\mathrm{S}$, when coalition $\mathrm{S}$ builds with landscape consideration and coalition N-S does not. Accordingly, the second equation of the top right, $(n-s)^{2} V$, refers to the cost to coalition $\mathrm{N}-\mathrm{S}$, when coalition $\mathrm{S}$ builds with landscape consideration and coalition N-S does not. Next, concerning the first equation on the bottom left, 
$s^{2} V$, it indicates the cost to coalition $S$ when coalition $S$ does not build with landscape consideration and coalition N-S does. The second equation on the bottom left,

$(n-s)(U+s V)$, refers to the cost to coalition $\mathrm{N}-\mathrm{S}$, when coalition $\mathrm{S}$ does not build with landscape consideration and coalition N-S does. Finally, the first equation on the bottom right, $s n V$, represents the cost to coalition $S$ when both coalition $S$ and coalition $N-S$ does not build with landscape consideration. The last equation on the bottom right, $(n-s) n V$, indicates the cost to coalition N-S when both coalition $S$ and coalition N-S does not build with landscape consideration.

The cost function for each situation

\begin{tabular}{|c|c|c|c|}
\hline \multicolumn{2}{|c|}{} & \multicolumn{2}{|c|}{$\mathrm{N}-\mathrm{S}$} \\
\cline { 3 - 5 } \multicolumn{2}{|c|}{$S$} & Landscape Considerate & Landscape Inconsiderate \\
\hline \multirow{3}{*}{$S$} & $\begin{array}{c}\text { Landscape } \\
\text { Considerate }\end{array}$ & $s U \quad(n-s) U$ & $s\{U+(n-s) V\} \quad(n-s)^{2} V$ \\
\cline { 2 - 5 } & $\begin{array}{c}\text { Landscape } \\
\text { Inconsiderate }\end{array}$ & $s^{2} V \quad(n-s)(U+s V)$ & $s n V \quad(n-s) n V$ \\
\hline
\end{tabular}

When the cost to coalition $S$ is greater when coalition $S$ builds with landscape consideration and coalition $N$-S does not; than the cost to coalition $S$ when both coalition $S$ and coalition $N-S$ do not build with landscape consideration,

$$
s\{U+(n-s) V\}>\operatorname{sn} V
$$

is derived and the following has been obtained:

$$
s<U_{V}
$$

In other words, this implies that when the number of supporters of the landscape agreement is less than a certain level, the landscape agreement is not established. For example, it identifies that a landscape agreement is not formed when the number of supporters of the landscape agreement is less than the ratio of the cost of building with landscape consideration to the cost of building without. On the other hand, when the cost to coalition $S$ when coalition $S$ builds with landscape consideration and coalition $N$-S does not is less than the cost to coalition $S$ when both coalition $S$ and coalition $N$-S do not build with landscape consideration,

$$
s\{U+(n-s) V\}<s n V
$$

is derived and from $n \geq s_{v}$ the following is obtained:

$$
n \geq s>U_{V}
$$

Hence, this suggests that only when the number of supporters of the landscape agreement is over a certain level, the landscape agreement is established. Furthermore, it has confirmed that when the number of supporters of the landscape agreement is greater than the ratio of the cost to build with landscape consideration to the cost of building without, the landscape agreement 
is formed. Moreover, the greater is the number of supporters of the landscape agreement, the cheaper is the cost of each household to improve the deterioration of the landscape. This shows that the most favourable outcome is when there is a universal support of the landscape agreement. However, a universal agreement in the area is not always attainable. We have next attempted to examine the conditions for not achieving a consensus with all households in an area.

Here, we have first assumed that coalition $S$ was formed and a landscape agreement was established and the buildings with landscape consideration were conducted based on this. The cost to the remaining coalition $N$-S to build with landscape consideration and the cost to build without will be $(n-s) U(n-s)^{2} V$ respectively. When the cost of building with landscape consideration is greater than building without consideration, the following has been obtained:

$$
(n-s) U>(n-s)^{2} V
$$

(3) can be rewritten as follows:

$$
n-s<U / V
$$

Hence, on the basis that there is a coalition $S$ that builds with landscape consideration, and the number in the remaining coalition $N-S$ is less than the ratio of the cost of building with landscape consideration to the cost of building without, it suggests that coalition $N-S$ will not form a landscape agreement.

From these results, we have learned that there is a case where the cost to coalition $S$ is less when it builds with landscape consideration than without and the cost is cheaper for coalition $N-S$ to build without. In this case, if we consider that coalition $S$, building with landscape consideration provides an external economy to the local area which impacts coalition $\mathrm{N}-\mathrm{S}$, then coalition $\mathrm{N}$-S can be considered a free rider. From this, the dominant strategy for each coalition $S$ and coalition $N-S$ will be (building with landscape consideration, building without landscape consideration) and this strategy becomes the equilibrium point. In other words, this identifies the possibility of two groups emerging, one that supports the active consideration of the landscape and one that is passive. This suggests that the group that actively supports building with landscape consideration will not exceed the border of $u / v$. Hence, a universal support of the landscape agreement will not be formed which is considered a shortcoming of landscape agreements.

Here, in order to simplify the conditions of the establishment of landscape agreements, we have considered the following policies. First, to encourage building with landscape consideration, the implementation of a subsidy to reduce the burden to each household is needed. The subsidy will be provided based on a standard rate $h$ which is applied to the per unit area cost of building with landscape consideration. Hence, the cost to each household will be $U(1-h)$. The second policy is the implementation of a penalty when building without landscape consideration. The penalty cost has been applied at a standard rate $p$ to the per unit area of cost of building without landscape consideration. Hence, the cost to each household will be $v(1+p)$.

In the next section, we have analysed these cases where the implementation of subsidies and penalties are both introduced. When both subsidies and penalties are introduced, coalition $S$ and coalition $\mathrm{N}$-S may each build with or without landscape consideration. Hence, the cost function for each situation is represented in Table 2 below. The first equation in the top left of 
Table 2, $s U(1-h)$, refers to the cost to coalition $S$ when both coalition $S$ and coalition $N-S$ build with landscape consideration. The second equation, $(n-s) U(1-h)$, indicates the cost to coalition $N-S$, when both coalition $S$ and coalition $N-S$ build with landscape consideration. The first equation in the top right, $s\{U(1-h)+(n-s) V(1+p)\}$ represents the cost to coalition $S$, when coalition $S$ builds with landscape consideration and coalition $N-S$ does not. Hence, the second equation of the top right, $(n-s)^{2} V(1+p)$, refers to the cost to coalition $N-S$, when coalition $S$ builds with landscape consideration and coalition $N-S$ does not. Next, concerning the first equation on the bottom left, $s^{2} V(1+p)$, it indicates the cost to coalition $S$ when coalition $S$ does not build with landscape consideration and coalition $N-S$ does. The second equation on the bottom left, $(n-s)\{U(1-h)+s V(1+p)\}$, refers to the cost to coalition $N-S$, when coalition $S$ does not build with landscape consideration and coalition $N-S$ does. Finally, the first equation on the bottom right, $\operatorname{snV}(1+p)$, represents the cost to coalition $S$ when both coalition $S$ and coalition $N-S$ does not build with landscape consideration. The remaining equation on the bottom right, $(n-s) n V(1+p)$, indicates the cost to coalition $N-S$ when both coalition $S$ and coalition $N$-S does not build with landscape consideration.

Table 2

The cost function for each situation when there are landscape policies (subsidies and penalties)

\begin{tabular}{|c|c|c|c|}
\hline & \multicolumn{2}{|l|}{$N-S$} \\
\hline & & Landscape Considerate & Landscape Inconsiderate \\
\hline \multirow[t]{2}{*}{$S$} & $\begin{array}{l}\text { Landscape } \\
\text { Considerate }\end{array}$ & $s U(1-h),(n-s) U(1-h)$ & $\begin{array}{l}s\{U(1-h)+(n-s) V(1+p)\} \\
(n-s)^{2} V(1+p)\end{array}$ \\
\hline & $\begin{array}{l}\text { Landscape } \\
\text { Inconsiderate }\end{array}$ & $\begin{array}{l}s^{2} V(1+p) \\
(n-s)\{U(1-h)+s V(1+p)\}\end{array}$ & $\operatorname{snV}(1+p), \quad(n-s) n V(1+p)$ \\
\hline
\end{tabular}

When the cost to coalition $S$ is greater when coalition $S$ builds with landscape consideration and coalition $N$-S does not; then, the cost to coalition $S$ when both coalition $S$ and coalition $N-S$ do not build with landscape consideration, $s\{U(1-h)+(n-s) V(1+p)\}>\operatorname{sn} V(1+p)$ is derived and the following is obtained:

$$
s<\frac{U(1-h)}{V} /(1+p)
$$

Proposition 1:

When there are subsidies and penalties and the number of supporters of the landscape agreement is less than the ratio of the cost of building with landscape consideration and 'the reduction in cost from the subsidy'; to the cost of building without landscape consideration and 'the cost from the penalty'; a landscape agreement will not be formed.

Hence, as in the case where there are no policies for building with or without landscape consideration, it implies that when the number of supporters of the landscape agreement is less than a certain level, landscape agreements will not be established. Furthermore, the number of supporters required for a landscape agreement is less when there are subsidies for households to build with landscape consideration and penalties for the lack of consideration than when there are no regulations or incentives. 
On the other hand, when the cost to coalition $S$ when building with landscape consideration and coalition $N-S$ builds without is less than when both coalition $S$ and coalition $N-S$ builds without landscape consideration $s\{U(1-h)+(n-s) V(1+p)\}<\operatorname{snV}(1+p) \quad$ is derived and from $n \geq s$, the following is obtained:

$n \geq s>{ }^{U(1-h)} / V(1+p)$

Proposition 2:

When there are policies such as subsidies and penalties in place and the number of supporters of the landscape agreement is greater than the ratio of the cost of building with landscape consideration with the reduction from the subsidy; to the cost of building without consideration with the added cost of the penalty; the landscape agreement is formed.

As in the case where there were no policies for landscape consideration, this implies that when the number of supporters of the landscape agreement is over a certain level, the landscape agreement is established. Compared to the case where there are no policies in place, we learn that a landscape agreement is formed with less number of supporters when there are subsidies and penalties in place to support the landscape considerate building.

Next, we have analysed the conditions for a landscape agreement not being established for coalition $N$-S. When a landscape agreement is formed to support building with landscape consideration and coalition $S$ is formed which builds with landscape consideration based on the agreement, the cost to the remaining coalition $N-S$ for when it builds with landscape consideration and when it builds without are represented by $(n-s)^{2} V(1+p)$ and $(n-s) U(1-h)$ respectively. When the cost of building without landscape consideration with the cost of the penalty applied is cheaper than building with landscape consideration with the reduction from the subsidy, the following applies:

$$
(n-s) U(1-h)>(n-s)^{2} V(1+p)
$$

It can be rewritten as follows:

$$
n-s<U(1-h) / V(1+p) \text {. }
$$

Proposition 3:

When coalition $S$ that builds with landscape consideration exists and the number of supporters of the remaining coalition $\mathrm{N}-\mathrm{S}$ is less than the ratio of the cost of building with landscape consideration including the subsidy; to the cost of building without consideration including the penalty; the landscape agreement is not formed by the remaining group $N$-S.

Compared to the case where there are no polices, it suggests that there is less room for free riders.

From the above results, we have learned that compared to the case where there are no policies to support landscape considerate building, by providing subsidies to support landscape considerate building and enforcing penalties when building without consideration, the support of the landscape agreement is promoted and it is effective in controlling free riders from those who do not support the agreement. 


\section{Conclusions}

As the need for a participatory approach for sustainable landscape planning and development has been recognised, there is an appetite to understand how local stakeholders can be encouraged to participate. The landscape agreements in Japan are such a method, but the success relies on the ability of the local stakeholders to come to an agreement and to reduce free riders.

This paper has focused on the mechanism of entering into a landscape agreement using the cooperative game model for analysis. The results of the analysis have confirmed that the landscape agreement can only be formed when a certain level of supporters exists and the optimal situation is when there is a universal agreement. On the other hand, the possibility of free riders has been confirmed which can cause the prevention of a universal agreement. Unlike the coalition game studies on international environmental agreements, where there is no authority that could implement and enforce environmental policies on sovereign states so the agreements need to be self-enforcing, landscape planning and agreements can be implemented on a local level and addressed by the existing government bodies. This has led to the further examination of the effect of subsidies for building with landscape consideration and the enforcement of penalties for inconsideration has on the ability to form landscape agreements and restricting free riders. As a result, it was found that compared to where there were no policies, subsidies and enforcement of penalties enabled landscape agreements to be formed with a fewer number of supporters and the number of free riders were also controlled. Furthermore, it was found that this effect was stronger when the size of the subsidy and penalty was greater. Hence, in order to increase the number of supporters of landscape agreements and control free riders, it is necessary to implement effective subsidy and penalty systems.

These results have the following policy implications. The first is the need to increase the capacity of providing subsidies which may be possible through the alignment and cooperation at the national, provincial and municipal levels as well as from the income of penalties. The subsidies may also be combined with other initiatives such as promoting the local region and economy where the colour, material, design and size of the development are taken into consideration to enhance the natural, cultural and historical landscape of the region. The increase in subsidies will also lead to the increased need of monitoring the actual development against the landscape plan. Concerning the penalties, in order to increase the effectiveness, there may be the need for the national, provincial and municipal government to establish policies that are legally binding and penalties can be enforced. It is especially important that qualitative indicators are stipulated with the quantitative indicators. National laws can define the framework and provincial measures can fill in the gaps in the national legislation and allocate financial responsibilities and lay down legal procedures. Practical guidelines for implementation such as a system to monitor and control the penalty system can be developed and administered at the municipal level. These results could also be applied to other landscape agreements with a participatory approach to increase its supporters. Further empirical analysis would be useful to test the robustness of the policy conclusions and to understand the optimal scheme for subsidies and penalties.

\section{References}

ALTAMIRANO-CABRERA J.-C., FINUS M. (2004), Permit trading and stability of international climate agreements, Journal of Applied Economics 9 (1), 19-47.

AMBEC S., SPRUMONT Y. (2002), Sharing a river, Journal of Economic Theory 107 (2), 453-462.

ANTROP M. (2005), Why landscapes of the past are important for the future, Landscape and Urban Planning 70 (1-2), 21-34. 
BOSELLO F., BUCHNER B., CARRARO C. (2003), Equity, Development, and Climate Change Control, Journal of the European Economic Association 1 (2-3), 601-611.

BRUNNER A., HUYTON H. (2009), The environmental impact of EU green box subsidies, in: Meléndez-Ortiz R., Bellmann C., Hepburn J. (eds.), Agricultural Subsidies in the WTO Green Box Ensuring Coherence with Sustainable Development Goals, Cambridge University Press, Cambridge, pp. 468-495.

BUCHECKER M., HUNZIKER M., KIENAST F. (2003), Participatory landscape development: overcoming social barriers to public involvement, Landscape and Urban Planning 64 (1-2), 29-46.

BUTLER A., ÅKERSKOG A. (2014), Awareness-raising of landscape in practice. An analysis of landscape character assessments in England, Land Use Policy 36, 441-449.

CARRARO C. (1999), The structure of international environmental agreements, in: Carraro C. (ed.), The structure of international environmental agreements, Springer, Dordrecht, pp. 9-25.

CARRARO C., EYCKMANS J., FINUS M. (2006), Optimal transfers and participation decisions in international environmental agreements, The Review of International Organizations 1 (4), 379-396

CARRARO C., SINISCALCO D. (1998), International institutions and environmental policy: International environmental agreements: Incentives and political economy, European Economic Review 42 (3-5), 561-572.

CARRARO C., SINISCALCO D. (2001), Transfers, commitments and issue linkage in international environmental negotiations, in: Ulph A. (ed.), Environmental Policy, International Agreements and International Trade, Oxford University Press, Oxford, pp. 19-37.

CHANDER P., TULKENS H. (1995), A core-theoretic solution for the design of cooperative agreements on transfrontier pollution, International Tax and Public Finance 2 (2), 279-293.

CHANDER P., TULKENS H. (1997), The core of an economy with multilateral environmental externalities, International Journal of Game Theory 26 (3), 379-401.

COUNCIL OF EUROPE (2008), Guidelines for the implementation of the European Landscape Convention, Retrieved from: www.coe.int.

CONRAD E., CHRISTIE M., FAZEY I. (2011), Understanding public perceptions of landscape: a case study from Gozo, Malta, Applied Geography 31 (1), 159-170.

EYCKMANS J., FINUS M. (2006), Coalition formation in a global warming game: How the design of protocols affects the success of environmental treaty-making, Natural Resource Modeling 19 (3), 323-358.

EYCKMANS J., TULKENS H. (2003), Simulating coalitionally stable burden sharing agreements for the climate change problem, Resource and Energy Economics 25 (4), 299-327.

GARROD G. D. (2007), Using the hedonic pricing model to value landscape features, Landscape Research 19 (1), 26-28.

GEOGHEGAN J., WAINGER L. A., BOCKSTAEL N. E. (1997), Spatial landscape indices in a hedonic framework: an ecological economics analysis using GIS, Ecological Economics 23 (3), 251-264.

HÖPPNER C., FRICK J., BUCHECKER M. (2007), Assessing psycho-social effects of participatory landscape planning, Landscape and Urban Planning 83 (2-3), 196-207.

HOSHI Y., KAWASAKI K. (2014), Current status of landscape agreements based on Landscape Law-Analysis of landscape agreements in Japan, Nihon-kenchiku-gakkai-taikaigakujyutsu-kouen-kougaishu, September, 897-900.

IOANNIDIS A., PAPANDREOU A., SARTZETAKIS E. (2000), International environmental agreements: A literature review, Cahiers de Recherche du GREEN 00-08, Québec.

KONG F., YIN H., NAKAGOSHI N. (2007), Using GIS and landscape metrics in the hedonic price modeling of the amenity value of urban green space: a case study in Jinan City, China, Landscape and Urban Planning 79 (3-4), 240-252. 
LINDBORG R., BENGTSSON J., BERG A., COUSINS S. A. O., ERIKSSON O., GUSTAFSSON T., PER HASUND K., LENOIR L., PIHLGREN A., SJÖDIN E., STENSEKE M. (2008), A landscape perspective on conservation of semi-natural grasslands, Agriculture, Ecosystems \& Environment 125 (1-4), 213-222.

SAITA H., MIWA K., KURIYAMA N., SAITO K. (2014), Study on the actual condition and the effect regarding the landscape guidelines in landscape administration, Nihon-kenchikugakkai-taikai-gakujyutsu-kouen-kougaishu, September, 1-2.

SANDER H. A., POLASKY S. (2009), The value of views and open space: Estimates from a hedonic pricing model for Ramsey Country, Minnesota, USA, Land Use Policy 26 (3), 837-845.

SATO Y. (2011), Landscape and community development, Bulletin of Faculty of Contemporary Social Studies Nagasaki Wesleyan University 9 (1), 31-40.

SEVENANT M., ANTROP M. (2010), Transdisciplinary landscape planning: Does the public have aspirations? Experiences from a case study in Ghent (Flanders, Belgium), Land Use Policy 27 (2), 373-386.

SHAPLEY L. S., SHUBIK M. (1969), On market games, Journal of Economic Theory 1 (1), 9-25.

SHIMADA S. (2013), The role of landscape act in townscape community planning, Konan Law Review 53 (3), 67-93.

TANZI V. (1998), Corruption around the world: causes, consequences, scope, and cures, IMF Staff Papers 45 (4), 559-594.

VALENCIA-SANDOVAL C., FLANDERS D. N., KOZAK R. A. (2010), Participatory landscape planning and sustainable community development: Methodological observations from a case study in rural Mexico, Landscape and Urban Planning 94 (1), 63-70.

WANG S., FAN J., ZHAO D., WU Y. (2015), The Impact of government subsidies or penalties for new-energy vehicles: A static and evolutionary game model analysis, Journal of Transport Economics and Policy 49 (1), 98-114.

WILSON J. Q., KELLING G. L. (1982), Broken windows: the police and neighborhood safety, The Atlantic Monthly 249 (3), 29-38.

WUNDERLICH G. (1997), Land taxes in agriculture, The American Journal of Economics and Sociology 56 (2), 215-220.

ZHAO R., ZHOU X., HAN J., LIU C. (2016), For the sustainable performance of the carbon reduction labeling policies under an evolutionary game simulation, Technological Forecasting and Social Change 112, 262-274.

ZHUO H., WEI S. (2017), Gaming of green supply chain members under government subsidies-Based on the perspective of demand uncertainty, in: Xu J., Hajiyev A., Nickel S., Gen M. (eds.), Proceedings of the Tenth International Conference on Management Science and Engineering Management. Advances in Intelligent Systems and Computing, Springer, Singapore, pp. 1105-1116.

Initial submission: 02.11.2016

Revised submission: 30.11 .2017

Final acceptance: 14.12.2017

Correspondence: Hirao School of Management, Konan University, 8-33 Takamatsucho, Nishinomiya, Hyōgo Prefecture 663-8204, Japan

Email: ken_japan51@hotmail.com 